\title{
SCRAM TESTS TO DETERMINE SHUTDOWN TRANSIENT CHARACTERISTICS OF THE ENRICO FERMI REACTOR AND ASSOCIATED HEAT TRANSPORT SYSTEM
}

M. A. Ziniuk

H. A. Wilber*

*Presently with Power Reactor Development Company 


\section{DISCLAIMER}

This report was prepared as an account of work sponsored by an agency of the United States Government. Neither the United States Government nor any agency Thereof, nor any of their employees, makes any warranty, express or implied, or assumes any legal liability or responsibility for the accuracy, completeness, or usefulness of any information, apparatus, product, or process disclosed, or represents that its use would not infringe privately owned rights. Reference herein to any specific commercial product, process, or service by trade name, trademark, manufacturer, or otherwise does not necessarily constitute or imply its endorsement, recommendation, or favoring by the United States Government or any agency thereof. The views and opinions of authors expressed herein do not necessarily state or reflect those of the United States Government or any agency thereof. 


\section{DISCLAIMER}

Portions of this document may be illegible in electronic image products. Images are produced from the best available original document. 
$\bullet$

c

. 


\section{FOREWORD}

This report is one of a series of reports on the low-power (up to $1 \mathrm{Mwt}$ ) and high-power (up to $200 \mathrm{Mwt}$ ) nuclear testing of the Enrico Fermi reactor. The Nuclear Test Program is planned, directed, and evaluated by Atomic Power Development Associates, Inc. (APDA). The tests are conducted by Power Reactor Development Company (PRDC), who own and operate the reactor proper. The steam generators and electrical generation facilities are owned by The Detroit Edison Company (DECo).

Many people have contributed to the success of the nuclear testing of the Fermi reactor. Listed below are the names of those people, exclusive of the authors, who made a significant contribution to some phase of the work reported in this document.

\section{APDA}

A. E. Klickman

M. L. Batch

A. J. Friedland

E. Halas

C. C. Scott
$\underline{P R D C}$

D. Erdman

P. M. Harrigan 


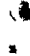




\section{TABLE OF CONTENTS}

$\underline{\text { Section }}$

Title

$\underline{\text { Page }}$

LIST OF ILLUSTRATIONS

vii

LIST OF TABLES

viii

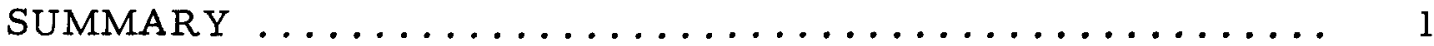

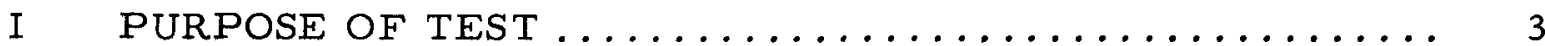

II GENERAL DESCRIPTION OF THE

ENRICO FERMI REACTOR $\ldots \ldots \ldots \ldots \ldots \ldots \ldots \ldots \ldots$

III EXPERIMENTAL APPARATUS AND EQUIPMENT ........ 9

A. TEMPERATURE DETECTORS ............... 9

1. Reactor Outlet Temperature ................. 9

2. Core Outlet Temperature .................. 9

3. Steam Generator Sodium Inlet Temperature ........ 11

4. Steam Generator Sodium Outlet Temperature ....... 11

5. Reactor Inlet Temperature ................ 12

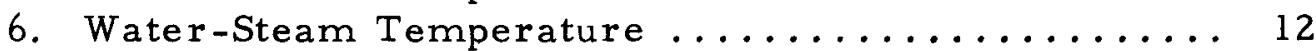

7. Neutron Flux ...................... 12

B. SCRAM EXECUTION ..................... 12

C. SIGNAL CONDITIONING CIRCUITS AND

ADJUNC TIVE APPARATUS ................ 14

IV EXPERIMENTAL PROCEDURES AND PLANT CONDITIONS .. 19

$\mathrm{V}$ EXPERIMENTAL RESULTS AND ANALYSIS .......... 23

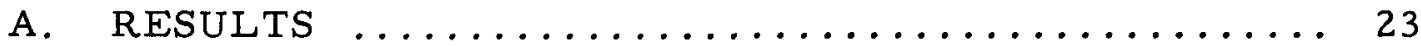

B. ANALYSIS ........................... 23

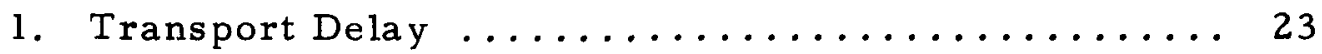

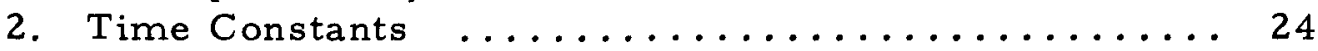

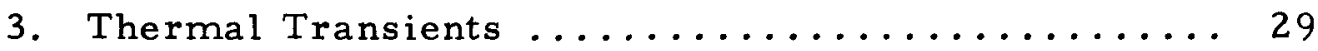

4. Plant Parameter Values.................. 32

5. Parameter Response Characteristics ........... 32

a. Core Outlet Temperature ............... 32

b. Reactor Sodium Outlet Temperature ......... 32

c. Reactor Inlet Temperature .............. 34

d. Steam Generator Sodium Inlet Temperature .... 34 
e. Steam Generator Sodium Outlet Temperature .... 34

f. Water-Steam Temperature .............. 35

g. Feedwater Flow ................... 35

h. Regulating Rod Position ............... 35

i. Neutron Flux ..................... 35

VI CONCLUSIONS $\ldots \ldots \ldots \ldots \ldots \ldots \ldots \ldots \ldots \ldots \ldots \ldots \ldots \ldots \ldots \ldots$

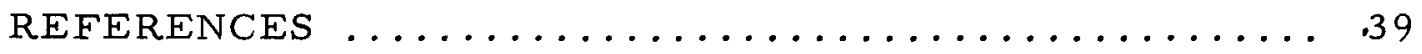




\section{LIST OF ILLUSTRA TIONS}

Figure

$\underline{\text { Title }}$

$\underline{\text { Page }}$

$1 \quad$ Perspective View of Reactor $\ldots \ldots \ldots \ldots \ldots \ldots \ldots \ldots \ldots \ldots \ldots \ldots \ldots \ldots$

2 Reactor Cross Section $\ldots \ldots \ldots \ldots \ldots \ldots \ldots \ldots \ldots \ldots \ldots \ldots$

3 Schematic Diagram of Temperature Detector Location in the Fermi Reactor Heat Transport System ........... 10

4 Location of Neutron Counter Tubes and Sodium Pipes in Graphite Shield ...................... 13

5 Bridge Circuit for Resistance Thermometer Detectors ..... 15

6 Temperature Detector Signal Circuits ............... 16

7 Transport Time Delays Determined from

Scram Transient Tests ...................... 26

8 Determination of Time Constants for TE-201-1

Response in Scram Test at $67 \mathrm{Mwt} \ldots \ldots \ldots \ldots \ldots \ldots \ldots$ 


\section{LIST OF TABLES}

Table

Title

$\underline{\text { Page }}$

I Scale Factors Used for Scram Test Recordings ........... 21

II Transport Time Delays of Temperature Transients Relative to the Instant of Neutron Flux Decay ............. 24

III Sodium Flow Rates in the Primary and Secondary Heat Transport Systems During Scram Tests.............. 25

IV Major Time Constant of Principal Temperature Parameters ... 27

V Maximum Design Transients.................. 30

VI Maximum Thermal Transients Derived from 67-Mwt Scram Test Recordings ..................... 31

VII Values of Plant Parameters Before and After

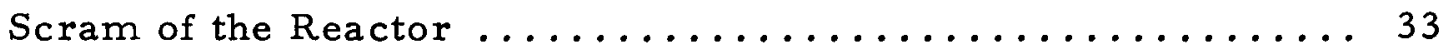




\section{SUMMARY}

Scram tests were performed at nominal reactor power levels of 9.5 , 13.3, 20, and 67 thermal megawatts. During the 9.5-,13.3-, and 67-Mwt tests, operation was on two coolant loops; whereas, during the $20 \mathrm{Mwt}$ test, operation was on three coolant loops. At $67 \mathrm{Mwt}$, significant thermal transients of the nature of random fluctuations were observed in the reactor outlet temperature as measured by the temperature detectors. The fluctuations first appeared approximately 15 seconds after the instant of scram and became most pronounced after about 40 seconds. Approximately 220 seconds after the scram, the fluctuations diminished to an imperceptible level. Thermal fluctuations and transients occurring in scrams at 9.5, 13. 3, and $20 \mathrm{Mwt}$ were insiginificant, apparently because of the low power levels involved. No significant fluctuations were observed in other system temperatures recorded.

Analysis by analog computer to correct for the detector and associated circuit time constants have produced thermal transient data representative of the actual thermal fluctuations measured by the temperature detectors. Results of the 67-megawatt test show that the most severe thermal transient was experienced at the reactor outlet in primary sodium loop No. 1, where a $44^{\circ} \mathrm{F}$-per-second transient was recorded over a temperature change of $76^{\circ} \mathrm{F}$. In primary sodium loop No. 2, the most severe transient experienced was $20^{\circ} \mathrm{F}$ per second over a $48^{\circ} \mathrm{F}$ temperature change. The original design specification for the Fermi reactor stipulates the worstcase temperature transient in the reactor outlet temperature to be $15.8^{\circ} \mathrm{F}$ per second for a change of $300^{\circ} \mathrm{F}$, with a maximum of 500 transients tolerable. Although the temperature rates of change experienced were comparatively high, the total change in temperature in each instance was well below the specification value.

Transport lags of the principal plant parameters were read from the scram test data obtained on strip chart recorders. Transport lags were somewhat smaller in the 67-Mwt case than at the lower reactor power levels. The difference is attributed to a slightly higher coolant flow rate at $67 \mathrm{Mwt}$. At this power, representative transport time for the reactor outlet sodium temperature is 11 seconds; for the steam generator inlet sodium temper ature, 62 seconds; for the reactor inlet sodium temperature, 70 seconds; and for steam generator water and steam temperature, 91 seconds. At the 9.5-, 13.3-, and 20-Mwt power levels, the transport lags are somewhat longer, with representative values of the above parameters being $12,70,100$, and 139 seconds, respectively. The difference in transport lags is attributed primarily to a higher flow rate for the 67-Mwt case. 
Performance of the scram interlocks and reset of the start-up interlocks also were of major interest during the scram tests. Performance of all interlock and reset circuitry, as well as operation of the reactor control system, was found to be satisfactory. 


\section{PURPOSE OF TEST}

The main objectives of the scram tests were to determine the characteristics of transients which occur in the principal plant parameters, to measure transport lags, to obtain the plant parameter time constants, and to verify correct performance of the scram interlock circuitry and reset of the start-up interlocks. Especially important among the interlock actions is reset of the safety rod raise interlock. 


\section{GENERAL DESCRIPTION OF THE ENRICO FERMI REACTOR}

The Enrico Fermi reactor, with its associated structures, is shown in perspective in Figure 1. The reactor is contained in a stainless steel vessel, sealed at the top by a rotating shield plug which supports the control mechanism, the fuel subassembly holddown mechanism, and the fuel subassembly handling mechanism. The reactor vessel is surrounded by borated and plain graphite neutron shielding material which is contained inside the primary shield tank. The reactor is of the fast-breeder type, cooled by sodium and operated at essentially atmospheric pressure. The maximum reactor power obtainable with the first core loading (Core A) is $200 \mathrm{Mwt}$.

The core and blanket region, located in the lower vessel, consists of 2.65-inch-square subassemblies containing the fuel pins and blanket rods. The core and blanket subassemblies are arranged to approximate a cylinder about 80 inches in diameter and 70 inches high. The core, which is contained in the central portion of the core subassemblies, approximates a right cylinder 31 inches in diameter and 31 inches high; it is axially and radially surrounded by the breeder blankets. The fuel in the first core loading consists of zirconium-clad pins containing U-10 w/o Mo alloy with the uranium enriched to $25.6 \mathrm{w} / \mathrm{o} \mathrm{U}-235$. Each subas sembly contains 140 fuel pins having a total mass of approximately $4.75 \mathrm{~kg}$ of $\mathrm{U}-235$. The blanket is depleted U-3 w/o Mo alloy.

The reactor cross section, shown in Figure 2, indicates the placement of individual components within the lower reactor vessel. There is a total of 149 central lattice positions used for core and inner radial blanket subassemblies and operating control and safety rods. All of these subassemblies are supplied with sodium coolant flowing upward from a plenum which is fed directly from the discharge of the primary sodium pumps. Owing to the large pressure drop across this region, through which about 90 per cent of the total sodium flows, subassemblies located in it require downward mechanical restraint in addition to their own weight in order to prevent ejection from the lower support plates. This restraint is supplied by the holddown mechanism.

The lattice positions sur rounding the inner radial blanket comprise the outer radial blanket area and, when filled with outer radial blanket subassemblies, form an annular region whose top and bottom are at the same elevation as the top and bottom of the inner radial blanket. Surrounding the outer radial blanket are lattice positions used for steel subassemblies which provide thermal and neutron shielding. The lattice positions occupied by outer radial blanket and shielding subassemblies a re supplied with sodium coolant from a low pressure plenum which is fed from the primary sodium 


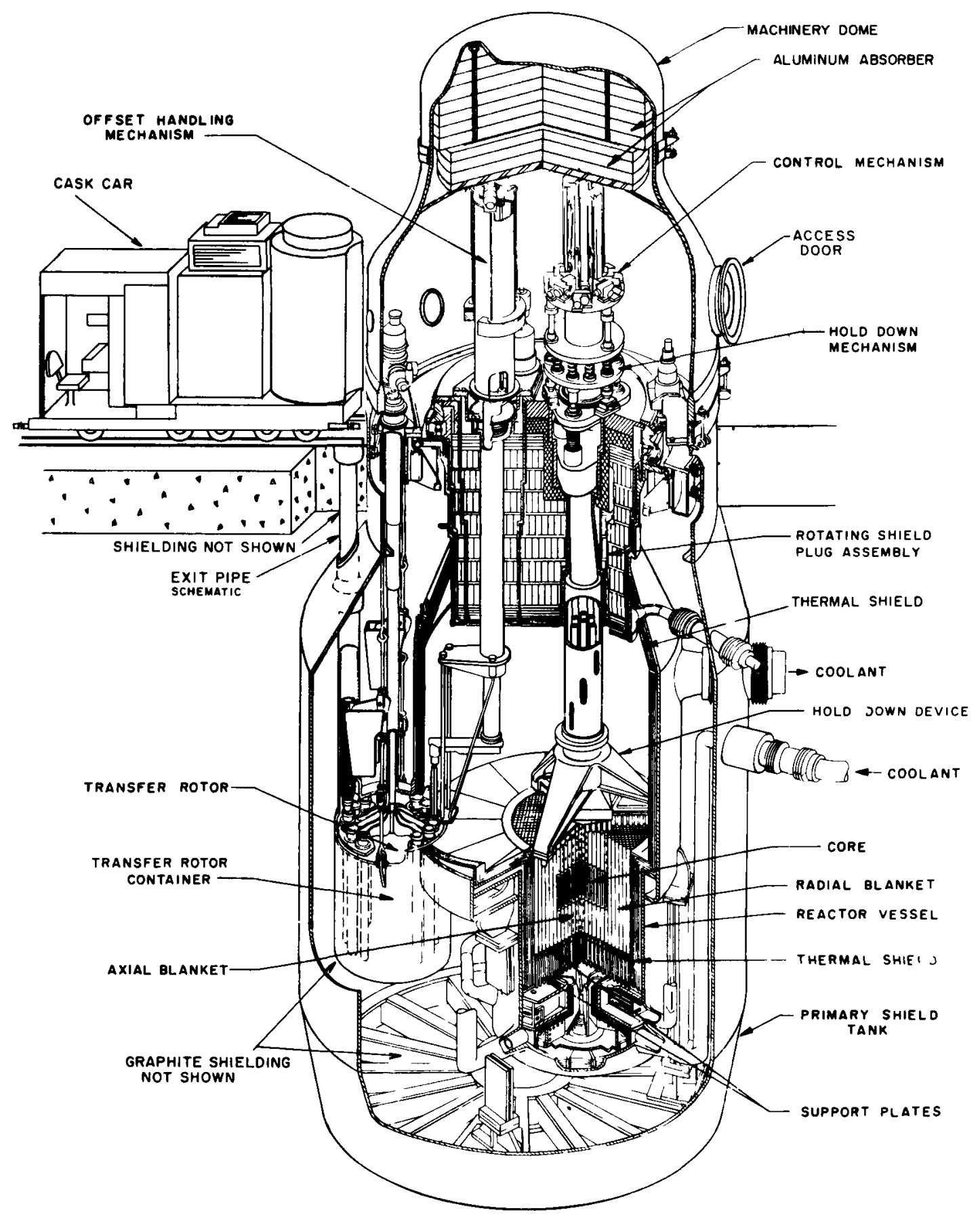

FIG. I PERSPECTIVE VIEW OF REACTOR 


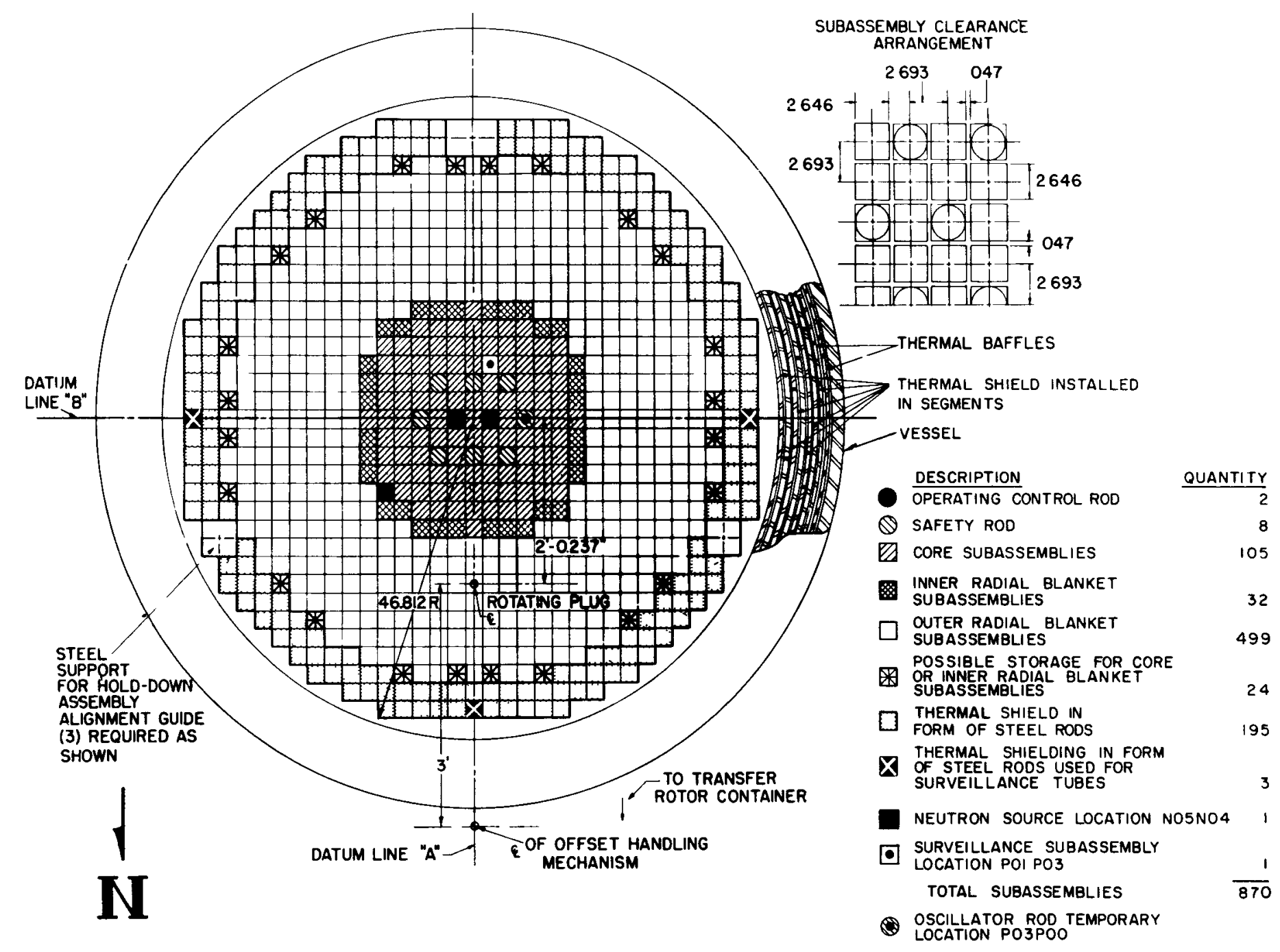

THE POSITION UNDER THE CENTER OF THE ROTATING PLUG, POONO9, IS VACANT 
pumps through throttle valves. The pressure drop force acting on these subassemblies is less than their weight; hence, no holddown mechanism is required.

Control of the reactor is accomplished by two operating control rods and eight safety rods. All the rods are of the poison type, made of $\mathrm{B}_{4} \mathrm{C}$ using boron enriched in B-10. One operating control rod is for regulating purposes and the other is for shimming; they have average reactivity insertion rates of about one cent per second and one cent per minute, respectively. Together they provide a total of 92 cents of reactivity to compensate for temperature override, burnup, and operating flexibility. The eight safety rods, which are spaced uniformly around and about seven inches from the vertical centerline of the core, provide a shutdown reactivity worth of over eight dollars. During reactor operation, the safety rods are poised just above the axial blanket section of the core so that they can be rapidly inserted into the core if it becomes necessary to scram the reactor. During normal operation, the safety rods are inserted slowly into the core, where they remain during refueling to provide the necessary shutdown reactivity.

The plant is designed for manual approach to criticality and to lowpower operation, and for either manual or automatic plant loading in the power range. Plant loading is determined by the reactor, not by system demand.

Heat produced in the reactor is removed by three primary coolant loops, all contained within the reactor building. Flow in the primary coolant system is up through the core and blanket into a large plenum region designated the upper reactor pool. Because the primary sodium is radioactive, its heat is transferred by three intermediate heat exchangers within the reactor building to three nonradioactive secondary sodium loops and finally to three once-through steam generators in the steam generator building. Here, steam is produced to operate the turbine in the adjacent turbine house.

A more detailed description of the Fermi reactor may be found in Reference 1 . 


\section{EXPERIMENTAL APPARATUS AND EQUIPMENT}

\section{A. TEMPERA TURE DETECTORS}

A brief description of the principal resistance temperature detectors (RTD's) and their physical locations and plant functions is presented below. Locations of the RTD's in the heat transport system are illustrated schematically in Fig. 3.

\section{Reactor Outlet Temperature}

The temperature detector used to sense reactor outlet temperature is a resistance thermometer ( TE-201) having a time constant of 6.07 seconds. 2,3 One such detector is provided in each of the three 30-inch reactor outlet pipes; mounting is in a well-type arrangement. The TE-201 detector is used in the reactor control system, reactor setback system, and the feedwater flow control system. To avoid impairing the normal control functions of this detector, connection of the strip chart recorder was made at the output of the demodulator. The demodulator provides a low source impedance and thereby prevents introduction of reading errors due to loading by the input circuit of the recorder.

As backup for the TE-201 detectors, sheathed thermocouples (TE-217) having time constants of 1 second, a re located in the 30 -inch reactor outlet pipe. These detectors, specifically intended to be replaceable, are located nearer the reactor proper than are the TE-201 detectors, i. e., they are inside the primary shield tank, while the TE-201 detectors are outside the primary shield tank but inside the secondary shield wall.

A 3/8-inch OD stainless steel guide tube connects the thermowell and the thermocouple installation port. The guide tubes for TE-217-1 and TE-217-3 are about 12 feet long and have two 60-degree bends; the offset in this line is about $2-1 / 2$ feet. It was evident from the response of TE-217-2 during the 20-and 67-Mwt scrams that the thermocouple was not properly seated in the thermowell. The thermal lag of TE-217-2 has been found to be about four times that of TE-217-3. The seating problem is probably the result of an accumulation of dirt in the thermowell.

\section{Core Outlet Temperature}

Fifty-five thermocouples (TE-115) are provided in the Fermi reactor to monitor the coolant outlet temperatures of the core subassemblies. As manufactured, these thermocouples have junctions grounded to the sheath for fast response, which is about 1 second. In several of the 


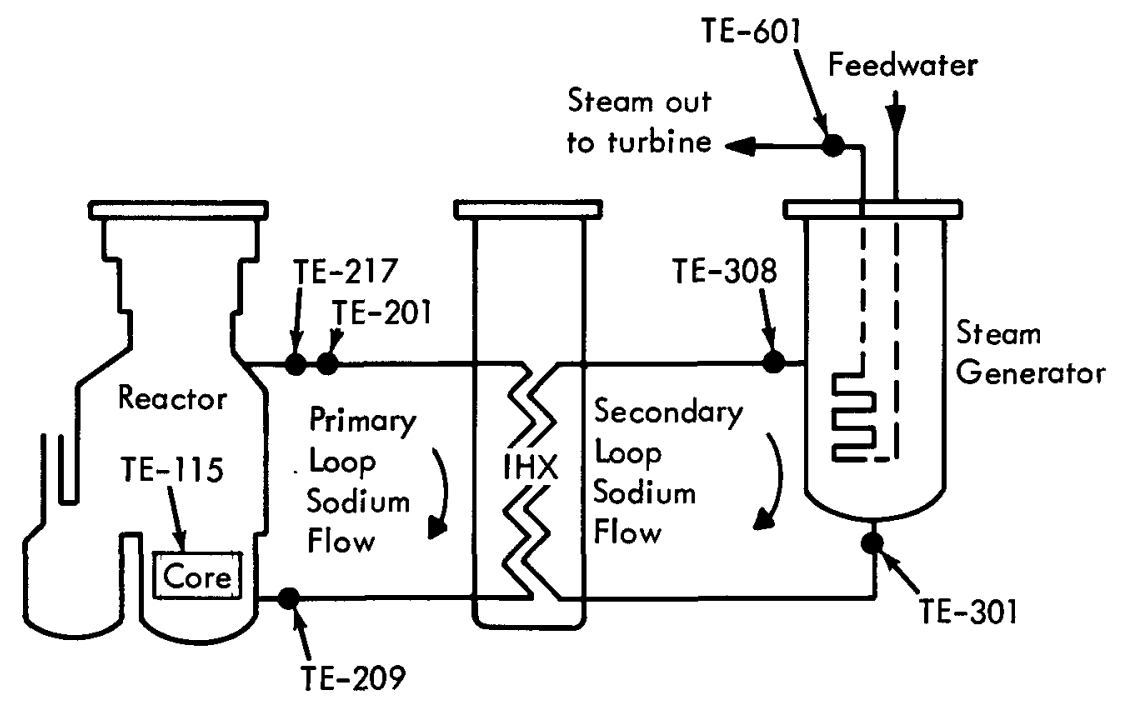

FIG. 3 SCHEMATIC DIAGRAM OF RESISTANCE TEMPERATURE DETECTOR LOCATIONS IN THE FERMI REACTOR HEAT TRANSPORT SYSTEM 
thermocouples the junctions have become ungrounded in the course of normal operations because of a difference of coefficients of linear expansion of the sheath and conductor materials. The response of an ungrounded thermocouple could be of the order of 5 seconds. Mounting inside the holddown finger is such that the thermocouple is close to the conical cavity which seats on the subassembly handling head.

The TE-115 detectors are used in the reactor safety system and core temperature automatic scanner and alarm. Core outlet temperature signals from four TE-115 thermocouples each control bistable multivibrators which feed the 2-out-of-4 AND gate logic circuit in the safety system. The AND gate is connected in such a manner that two "unsafe" signals must be present before an "unsafe" signal is applied to the scram logic OR gates, scramming the reactor.

\section{Steam Generator Sodium Inlet Temperature}

The steam generator sodium inlet temperature is monitored by resistance-type temperature sensors (TE-308) mounted in thermowells in the 18 inch pipe of the inlet piping system to the steam generator. More specifically, the location of the detectors is in the region of the $\mathrm{T}$-connection in the 18-inch pipe which splits the steam generator inlet sodium flow to the two 12 -inch inlet nozzles of the steam generator. The time constant of this sensor is about 25 seconds.

The TE-308 detectors have no normal control function but provide information to an indicator in the control room. A pneumatic retransmitter is used to drive this indicator. To obtain a signal from the RTD, a separate bridge circuit was provided. A suitable scale factor was set up for the recorder by means of the recorder gain adjustment.

\section{Steam Generator Sodium Outlet Temperature}

The steam generator outlet temperature is used as one of the basic signals in the feedwater control system to establish a demand signal for feedwater flow. Emergency feedwater flow also is controlled by the steam generator sodium outlet temperature. The detector originally provided in the steam generator outlet piping is a resistance thermometer (TE-301) located about $1-1 / 2$ feet from the bottom of the steam generator vessel. Response of the detector is estimated to be 2.5 seconds. Early in the reactor test program it was observed that flow channeling of relatively hot sodium along the walls of the steam generator sodium outlet piping was producing high,erratic readings of TE-301 because of poor mixing at this point. To obtain a better temperature signal, thermocouples were installed in thermowells about 75 equivalent pipe diameters downstream from the original TE-301 location. The thermocouples in- 
stalled in each loop carry the designations D, E, and $F$. The response of the basic thermocouple is about 1.5 seconds.

In setting up the recorder scale factors for the 67-Mwt scram test, the output of the TE-301-2D1 thermocouple was observed to have a high-level, 60-cycle extraneous signal, preventing recording of the temperature information. The difficulty was diagnosed to be a ground fault somewhere in the thermocouple extension leads.

\section{Reactor Inlet Temperature}

The reactor inlet temperature detector (TE-209) is located in the 6-inch standpipe. The $\mathrm{TE}-209$ temperature detector is a resistance thermometer identical with the TE-201, and also has a time constant of 6.07 seconds.

\section{Water-Steam Temperature}

The water-steam temperature signal (TE-601) is used in the reactor program controller and in the plant recorders and indicators. The TE-601, a resistance-type temperature detector thermowell-mounted in the outlet pipe of the steam generator, is the same type as the TE-308, and also has time constant of 25 seconds.

\section{Neutron Flux}

The neutron flux detector for measuring and monitoring reactor power was provided as a separate apparatus, independent of the reactor safety system and control instrumentation. The detector utilized was a B-10-lined compensated ion chamber (NE-116) installed in neutron-counter tube No. 5, shown in Figure 4. The output of the ion chamber is read on a Keithley Model 415 electrometer located in the control room. A coaxial cable approximately 250 feet long interconnects the ion chamber and the electrometer. The time constant of the neutron flux measuring instrumentation is of the order of 10 millis econds.

\section{B. SCRAM EXECUTION}

Briefly, the reactor scram circuit functions in the following manner: The SCRAM pushbutton is manually depressed to obtain a normal scram of the reactor. Since contacts of the scram switch are in series with the solidstate relay control circuit and scram coil power unit which supplies 28 volts average $d-c$ to the safety rod holding electromagnet, breaking of the circuit causes the holding electromagnet to be de-energized, thereby releasing the mechanical latch. The spring-loaded rod is then accelerated into the core at an average velocity of about 70 inches per second. This is equivalent to a rate of negative reactivity insertion of about $\$ 17$ per 


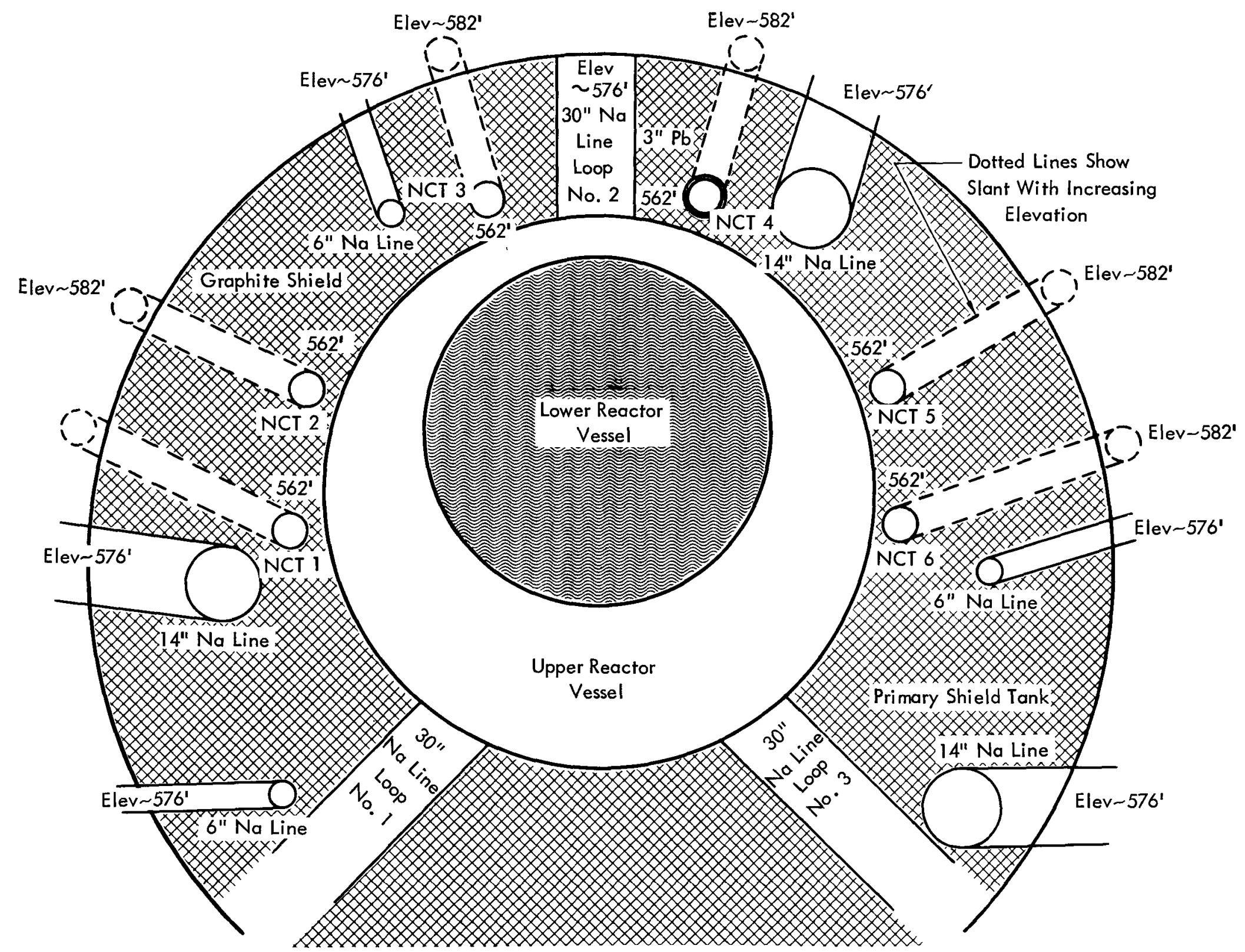

FIG. 4 LOCATION OF NEUTRON - COUNTER TUBES AND SODIUM PIPES IN GRAPHITE SHIELD 
second for eight rods dropping simultaneously. The release time from initiation of a scram signal to breakaway of the safety rods has been meas ured to be approximately 0.045 s econd.

Any scram signal, whether manually- or safety-system-introduced, energizes the fast drive motors for all the safety rods. These motors drive the safety rod extensions down into the core, requiring approximately 30 seconds to travel from the upper position to a point 6 inches above the lower position. The operating control rods a re not released during a scram, but are driven down at the setback rate of about 5.35 inches per minute.

\section{SIGNAL CONDITIONING CIRCUITS AND ADJUNCTIVE APPARATUS}

Since a signal was not always available in all cases to record a plant parameter, a special bridge cirucit had to be provided for some RTD's to enable their operation and calibration; the basic circuit is shown in Fig. 5 . With some detectors, special care had to be exercised to prevent upsetting the normal operation of the circuit by recorder loading or by accidental short circuit which could impair or otherwise alter the detector output signal. Inasmuch as the output of the TE-201 detectors has an important control function, the output of each TE-201 detector recorded was taken at the output of the demodulator, where the circuit impedance is low. An available spare $T E-301$ detector already in the system was placed into use for the tests. The TE-209 detector utilized was temporarily diverted from its normal function in the safety rod withdrawal interlock circuit. A signal from the TE-60l detector was obtained from the retransmitting slidewire of the plant recorder, into which the detector normally works. The TE-301 signal was obtained at the output of a load-isolating (low output impedance) preamplifier.

Figures $6 a, 6 b$, and $6 c$ are block diagrams of the circuits of the RTD's, and Figure 6d shows the circuit for the TE-301 thermocouples.

Adjunctive apparatus and equipment employed in the scram tests consisted of the following major items:

- Two eight-channel strip chart recorders, having a minimum response of $50 \mathrm{cps}$ and containing suppression and span calibrating provisions, were used for recording system parameters such as temperatures, regulator rod position, and neutron flux.

- A broadband, 4-channel, frequency-or amplitude-modulated signal tape recorder was used for recording the outputs of the TE-20l detectors and read-in of verbal narration. 


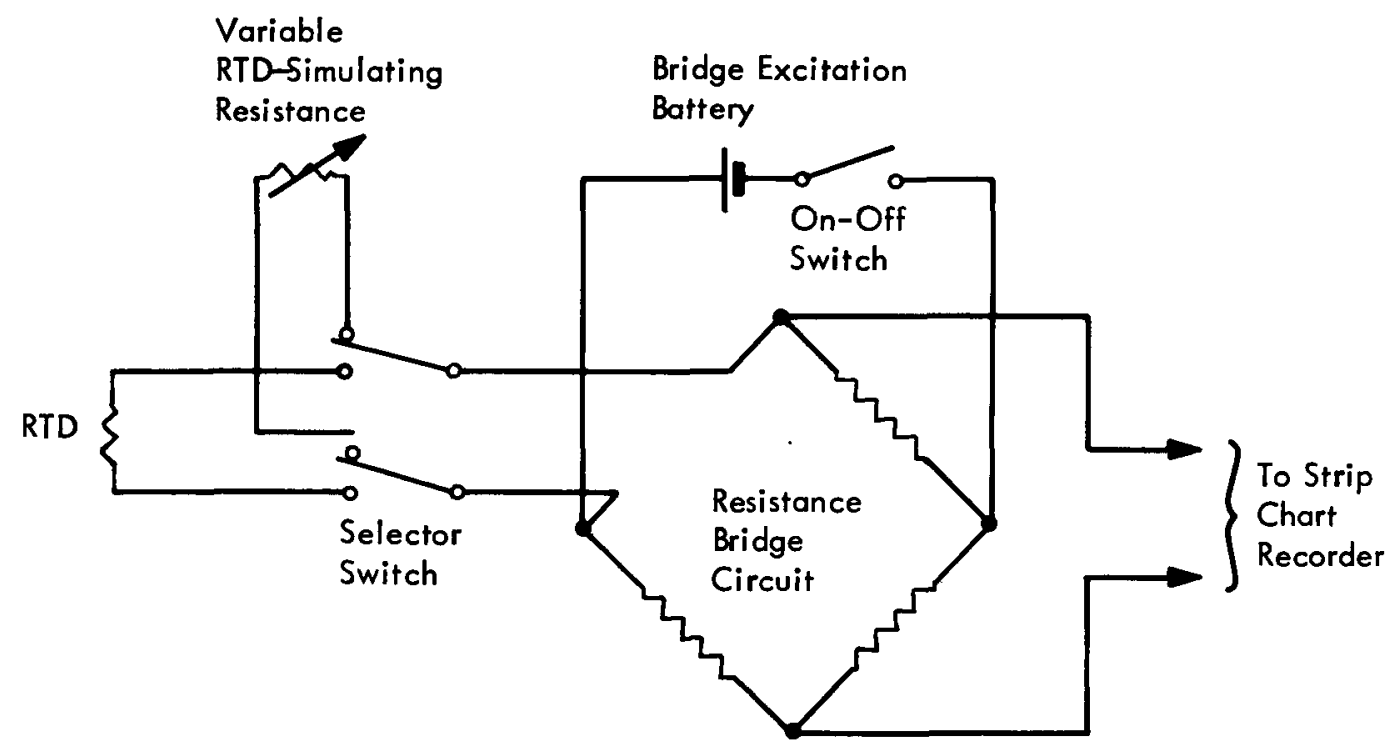

FIG. 5 BRIDGE CIRCUIT FOR RESISTANCE THERMOMETER DETECTORS 

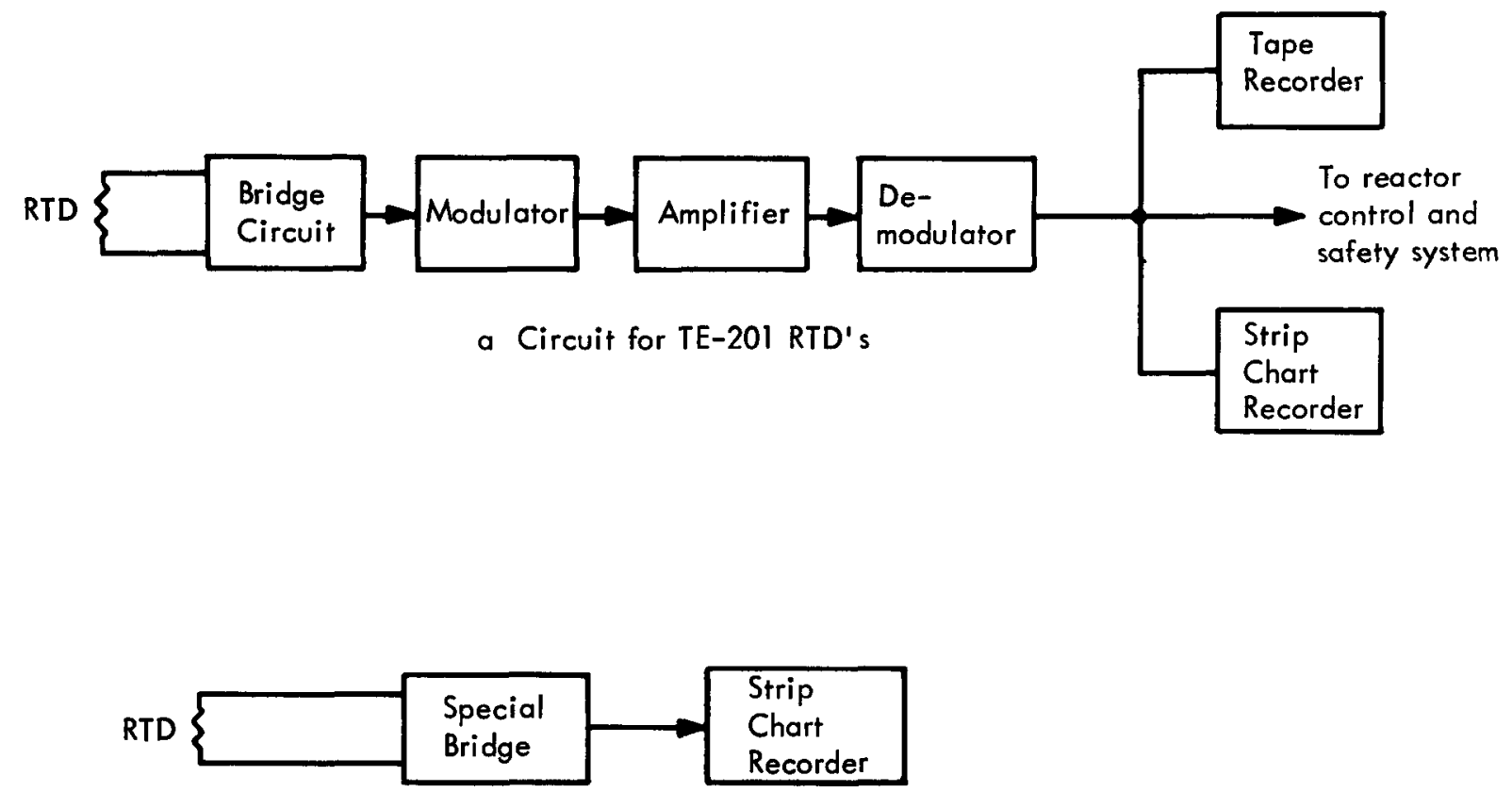

b Circuit for TE-209 and TE-308 RTD's
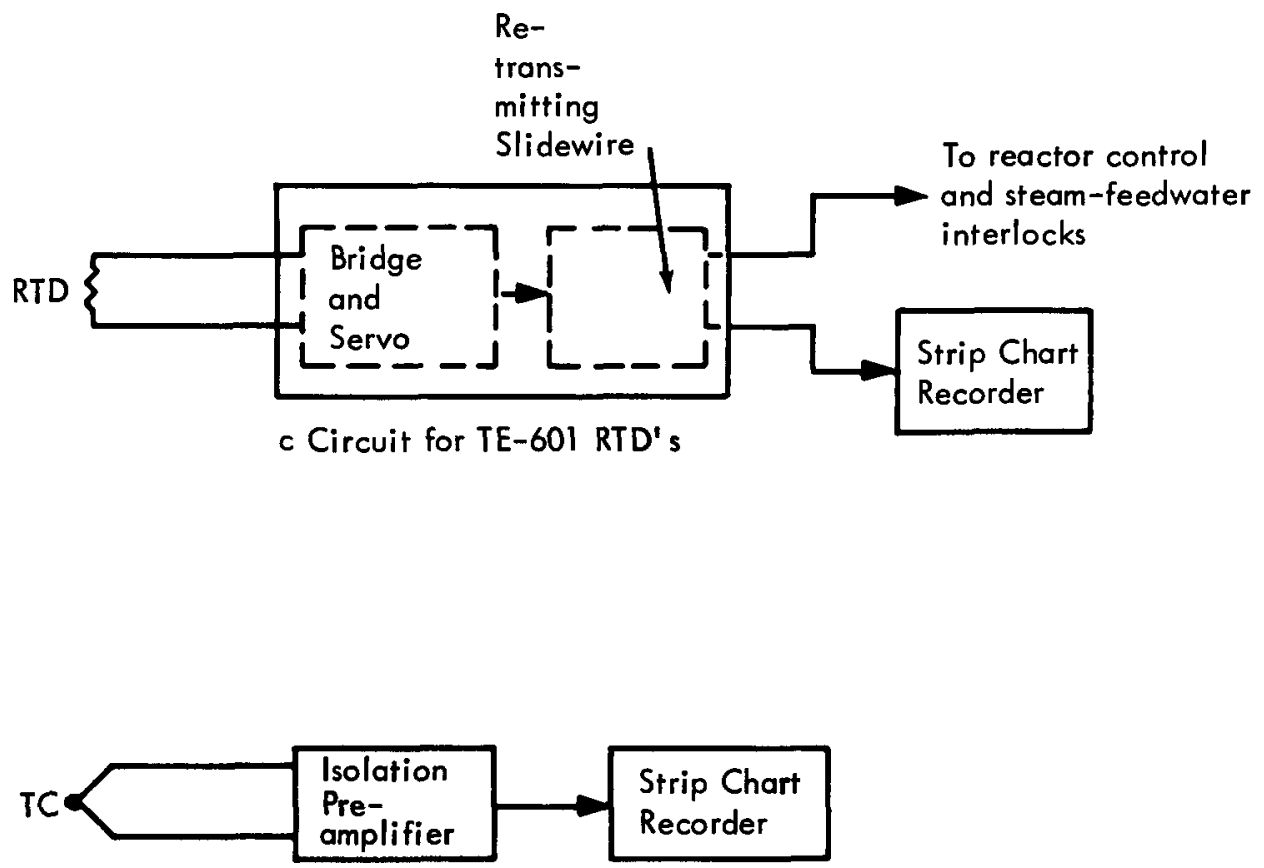

d Circuit for TE-301 Thermocouple Detector

FIG. 6 TEMPERATURE DETECTOR SIGNAL CIRCUITS 
- A millivolt box was used for simulating the output of a thermocouple.

- Three four-arm resistance bridge circuits equipped with a battery power supply for excitation of the bridge were used to simulate an RTD during recorder calibration and to provide the required bridge circuitry for operation of RTD's TE-209 and TE-308, apart from their respective plant recorders. 


\section{EXPERIMENTAL PROCEDURES AND PLANT CONDITIONS}

The reactor operating control system provides a choice of manual or automatic control. Manual control is primarily for start-up, test, and emergency use. Reactor start-up from source level up to about 10 megawatts is a manual operation under strict administrative control. Normally, the plant loading programmer controls the plant during run-up in the power range and during power level changes. Four of the five subsystems comprising the feedwater and steam control system also are operable in either manual or automatic control. The four subsystems which have this duality of operation are the feedwater flow control, feedwater pump speed control, steam generator pressure control, and the No. 4 heater pressure control. The fifth subsystem, the emergency feedwater flow control, operates only in the automatic mode.

Reactor control at the test power level in the scram tests was in the manual mode up to the instant of scram. Steam and feedwater controls also were in the manual mode. At 9.5, 13.3, and $67 \mathrm{Mwt}$, operation was on two coolant loops; whereas, for the 20-Mwt test, operation was on three coolant loops.

The basic steps in executing a reactor scram were as follows: First, the required nominal primary and secondary sodium flow rates were established; second, reactor power was brought to the desired test level in accordance with the prescribed plant operating procedures; third, feedwater flow was adjusted manually to establish a steam generator sodium outlet temperature consistent with the reactor power schedule. No special plant conditions or limitations were imposed to perform the tests. Plant parameters were read on the panel and console instruments and logged. The reactor was manually scrammed. After the transients resulting from the scram diminished to imperceptible levels, the plant parameters were again read and logged. Data recorded on strip chart recorders were as follows:

Reactor outlet temperature (TE-201)

Core outlet temperature (TE-115)

Steam generator sodium inlet temperature (TE-308)

Steam generator sodium outlet temperature (TE-301)

Reactor inlet sodium temperature (TE-209)

Water-steam temperature at steam generator (TE-601)

Feedwater flow

Neutron flux (NE-116)

Regulator rod position

Reactor outlet temperature (TE-217). 
The recorder scale factors used for the recordings are listed in Table I.

Data logged from the panel and console instruments were

Reactor outlet temperatures (TE-201-1, 2, 3)

Reactor inlet temperatures (TE-209-1,2,3)

Steam generator sodium inlet temperatures ( TE-308-1, 2, 3)

Steam generator sodium outlet temperature $(\mathrm{TE}-301-1,2,3)$

Feedwater temperature (E-50)

Steam temperature (TE-601-1C, 2C, 3C)

Primary sodium flows (FR-201-1, 2, 3 and FR-202-1, 2, 3)

Secondary sodium flows (FR-301-1, 2, 3)

Feedwater flows (FR-601-1, 2, 3)

Steam pressure (D-74)

Reactor power (NR-108)

The data obtained are on file in the reactor operations office at the Enrico Fermi plant. 
TABLE I - SCALE FACTORS USED FOR SCRAM TEST RECORDINGS

Recorder Scale Range *

\begin{tabular}{|c|c|c|c|c|}
\hline Parameter & $9.5 \mathrm{Mwt}$ & $13.3 \mathrm{Mwt}$ & $20 \mathrm{Mwt}$ & $67 \mathrm{Mwt}$ \\
\hline \multicolumn{5}{|c|}{ Temperature Recording, ${ }^{\circ} \mathrm{F}$} \\
\hline $\mathrm{TE}-115$ & $500-600$ & $500-600$ & $500-600$ & $500-800$ \\
\hline $\mathrm{TE}-201$ & $500-550$ & $500-550$ & $500-550$ & $500-700$ \\
\hline TE-209 & $500-550$ & $500-550$ & $500-550$ & $500-550$ \\
\hline $\mathrm{TE}-217$ & - & $500-550$ & $500-550$ & $500-700$ \\
\hline $\mathrm{TE}-301$ & $475-550$ & $475-550$ & $500-550$ & $500-550$ \\
\hline $\mathrm{TE}-308$ & $500-550$ & $500-550$ & $500-550$ & $500-700$ \\
\hline $\mathrm{TE}-601$ & $500-550$ & $100-600$ & $500-550$ & $500-700$ \\
\hline Steam Pressure, psig & - & - & - & $500-1000$ \\
\hline Feedwater Flow, lb/hr & - & - & - & $0-2 \times 10^{5}$ \\
\hline Neutron Flux, amps & $0-1 \times 10^{-5}$ & $0-1 \times 10^{-5}$ & $0-1 \times 10^{-5}$ & $0-3 \times 10^{-5}$ \\
\hline * Chart Width, cm & 5 & 5 & 5 & 5 \\
\hline Chart Speed, sec/cm & 10 & 4 & 10 & 10 \\
\hline
\end{tabular}


-

- 


\section{EXPERIMENTAL RESULTS AND ANALYSIS}

\section{A. RESULTS}

The plant parameters which were recorded on strip chart recorders to obtain transient and steady-state data are listed in Section IV. Parameter responses after the scram were observed for seven transient characteristics: transport delay, time constant, maximum rate of change, duration of the maximum rate of change, overshoot, oscillation, and settling time. Among these characteristics, the most important from the standpoint of plant safety and longevity are the maximum rate of change and its duration. Plant design criteria contained in Volume 1 of Reference 1 stipulates maximum values of parameter transients for various regions of the reactor system. One of the principal parameters is the temperature in the outlet nozzle region of the reactor, which is read by $T E-201$ detectors. Of major concern are the rate of change and duration of transients for the two-loop condition as compared to the three-loop condition at power levels of $67 \mathrm{Mwt}$ and higher. At relatively low reactor power levels, however, such as $20 \mathrm{Mwt}$ and less, thermal transient data are relatively insignificant because of the low heat levels involved. The tests at the low reactor power levels have their usefulness mainly in checking out the start-up provisions in the reactor and feedwater control systems and the plant interlock systems.

\section{B. ANALYSIS}

\section{Transport Delay}

Transport delay is the time lapse between the instant of initiation of the test and beginning of the transient response of the parameter observed. In reading the charts, the instant of initiation of the test is taken as occurring simultaneously with the beginning of decay of the neutron flux density signal following scram of the reactor. In Table II a re listed the transport delays of the principal plant parameters as read from the strip chart recordings; the delays are illustrated in a time plot in Figure 7, where the transport delays of the steam generator sodium inlet temperature (TE-308), reactor inlet sodium temperature (TE-209), and steam temperature at the steam generator ( $T E-601)$, are seen to be somewhat shorter for the 67-Mwt case than for the 20-Mwt case, despite the fact that operation at $67 \mathrm{Mwt}$ was on only two coolant loops, whereas in the latter case operation was on three coolant loops. The shorter transport time results from a slightly higher coolant flow rate at $67 \mathrm{Mwt}$.

The sodium flow rates in the primary and secondary coolant systems during the scram tests a re given in Table III. The negative flow 


$\begin{aligned} \text { TABLE II - } & \text { TRANSPOR T TIME DELAYS OF TEMPERATURE } \\ & \text { TRANSIENTS RELA TIVE TO THE INSTANT OF } \\ & \text { NEUTRON FLUX DECAY * }\end{aligned}$

Time Delay, sec

\begin{tabular}{|c|c|c|c|c|}
\hline Parameter & $9.5 \mathrm{Mwt}$ & $13.3 \mathrm{Mwt}$ & $20 \mathrm{Mwt} * *$ & $\underline{67 \mathrm{Mwt}}$ \\
\hline TE-115 & 1.5 & 1 & 1 & 1.5 \\
\hline$T E-201$ & 14 & 13 & 10 & 11 \\
\hline TE-209 & 106 & 100 & 97 & 70 \\
\hline TE -308 & 76 & 72 & 72 & 62 \\
\hline TE-301 & 116 & 112 & 112 & $* * *$ \\
\hline $\mathrm{TE}-601$ & 151 & 136 & 132 & 91 \\
\hline
\end{tabular}

* See Figure 7.

* Three-loop operation; two-loop operation in other tests.

*** Unobtainable because of parameter instability.

rate noted in some cases is due to the back pressure of the core inlet plenum (high pressure) and is indicated for the 14 -inch line in each case where the loop is not operative during the test. The relatively high forward flow in the 6-inch line exists due to the pressure in the 14-inch line. In the secondary system, where the three coolant loops are isolated from each other, no flows are indicated for those loops shut down because for all practical purposes, the flow is zero with the exception of convective circulation.

\section{Time Constants}

The time constants of principal plant parameters obtained during the 9.5-, 13.3-, 20-, and 67-Mwt scram tests are presented in Table IV. The value given for each parameter is that of the major time constant. Time constants of higher order are also present, but their effects on the overall response are small by comparison with the effect of the major time constant. For example, the recorded TE-201 response includes the lag effects of the 6.07-second time constant of the resistance thermometer. Also present in the recorded TE-201 response, though of lesser significance than the effect of the resistance thermometer, are the effects of the time constants of the signal amplifier and the strip chart recorder.

The time constant of TE-601 in the 67-Mwt case was influenced by manual adjustments of the feedwater flow rate; hence, the rather substantial differences between the value at $67 \mathrm{Mwt}$ and the values obtained at the lower power levels are attributed largely to the manual flow adjustments which were made following the scram. 
TABLE III - SODIUM FLOW RATES IN THE PRIMARY AND SECONDARY HEAT TRANSPORT SYSTEMS DURING SCRAM TESTS

Primary System Sodium Flow, $10^{6} \mathrm{lb} / \mathrm{hr}$

\begin{tabular}{|c|c|c|c|c|c|c|}
\hline \multirow{2}{*}{$\begin{array}{c}\text { Reactor } \\
\text { Power, } \\
\text { Mwt }\end{array}$} & \multicolumn{2}{|c|}{ Loop No. 1} & \multicolumn{2}{|c|}{ Loop No. 2} & \multicolumn{2}{|c|}{ Loop No. 3} \\
\hline & 14-Inch Line & 6-Inch Line & 14-Inch Line & 6-Inch Line & 14-Inch Line & 6-Inch Line \\
\hline 9.5 & 2.93 & 0.288 & -0.440 & 0.240 & 2.44 & 0.288 \\
\hline 13.3 & 2.99 & 0.300 & -0.330 & 0.255 & 2.70 & 0.300 \\
\hline 20 & 2.64 & 0.338 & 2.60 & 0.420 & 2.50 & 0.400 \\
\hline 67 & 2.93 & 0.310 & 3.13 & 0.305 & -0.450 & 0.287 \\
\hline Reactor & \multicolumn{6}{|c|}{ Secondary System Sodium Flow, $10^{6} \mathrm{lb} / \mathrm{hr}$} \\
\hline $\begin{array}{c}\text { Power, } \\
\text { Mwt }\end{array}$ & \multicolumn{2}{|c|}{ Loop No. 1} & \multicolumn{2}{|c|}{ Loop No. 2} & \multicolumn{2}{|c|}{ Loop No. 3} \\
\hline 9.5 & \multicolumn{2}{|c|}{2.95} & \multicolumn{2}{|c|}{-} & \multicolumn{2}{|c|}{ 3. 10} \\
\hline 13.3 & \multicolumn{2}{|c|}{2.98} & \multicolumn{2}{|c|}{-} & \multicolumn{2}{|c|}{ 2. 90} \\
\hline 20 & \multicolumn{2}{|c|}{2.91} & \multicolumn{2}{|c|}{2.95} & \multicolumn{2}{|c|}{2.92} \\
\hline 67 & \multicolumn{2}{|c|}{2.88} & \multicolumn{2}{|c|}{3.18} & \multicolumn{2}{|c|}{-} \\
\hline
\end{tabular}


67-Mwt 2-Loop Operation

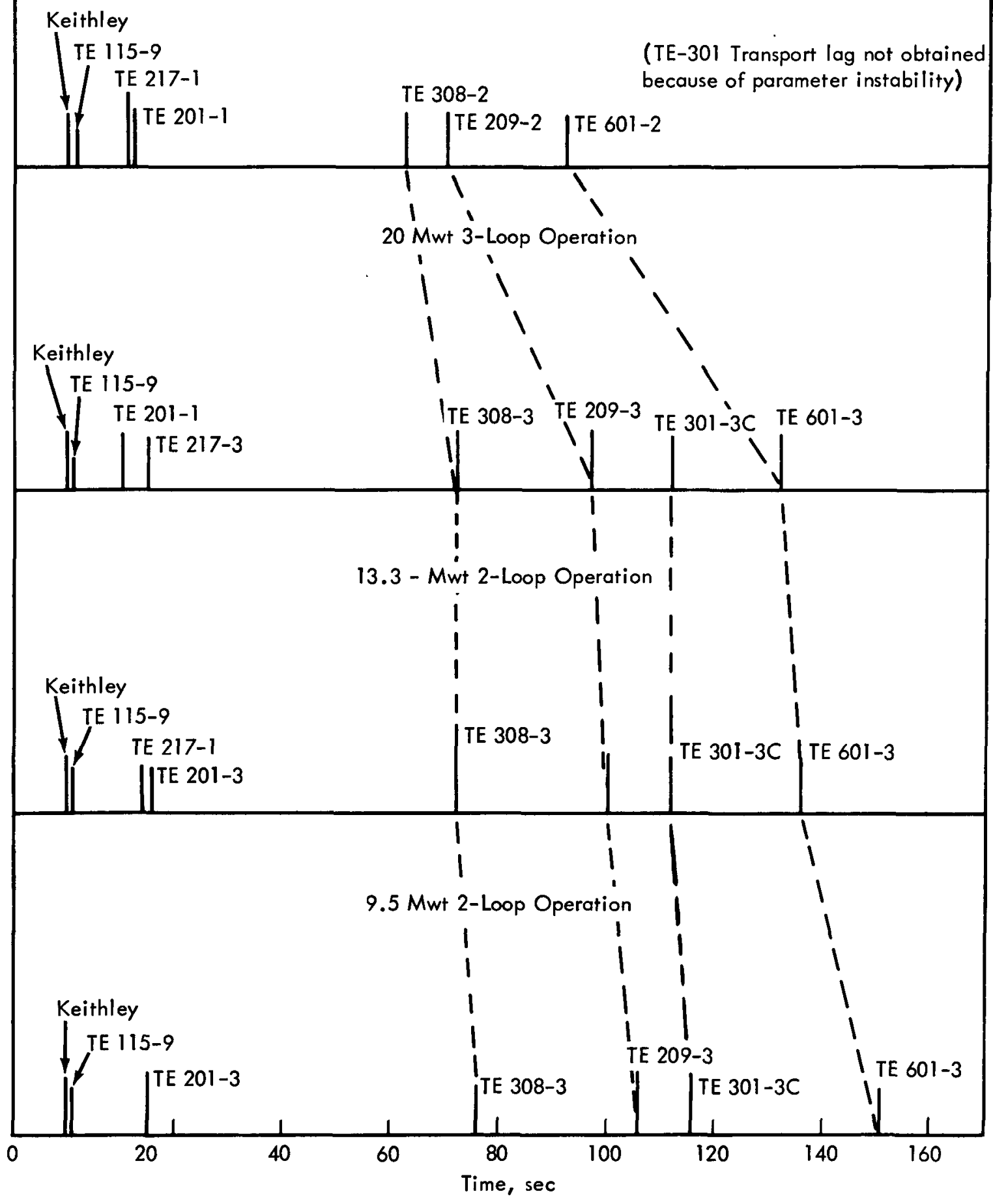

FIG. 7 TRANSPORT TIME DELAYS AS DETERMINED FROM SCRAM TRANSIENT TESTS 
TABLE IV - MAJOR TIME CONSTANT OF PRINCIPAL TEMPERA TURE PARAMETERS

Time Constant, sec

\begin{tabular}{|c|c|c|c|c|}
\hline Parameter & $9.5 \mathrm{Mwt}$ & $13.3 \mathrm{Mwt}$ & $20 \mathrm{Mwt}^{*}$ & $67 \mathrm{Mwt}$ \\
\hline$T E-115$ & 1.5 & 1.5 & 1.5 & 1.5 \\
\hline$T E-201$ & 57 & 47 & 30 & 48 \\
\hline TE-209 & 58 & 67.5 & 77 & 87.5 \\
\hline TE-308 & 87 & 75 & 84 & 75 \\
\hline$T E-301-2 D 1$ & 63 & 90 & 87 & $* *$ \\
\hline$T E-601$ & 95 & 92 & 88 & 110 \\
\hline
\end{tabular}

* Three-loop operation; operation on 2 loops in other tests. * Unobtainable because of parameter instability.

A graphical method was employed in obtaining the time constants in Table IV. Basically, the procedure consists of plotting on semilog graph paper the percentage of incompleteness of the transient and determining from the plot the time required for the incompleteness to diminish to 36.8 per cent of its initial value. This technique is commonly employed in the analysis of process control systems.

Illustrated in Fig. 8 is the plot from which was obtained the major time constant of the TE-201-1 response for the 67-Mwt scram. The technique proceeds as follows: First, the percentage of incompleteness of the transient response is plotted on semilog graph paper, with incompleteness on the log axis and time on the linear axis. Second, the linear portion of the curve, designated $A$ in Fig. 8, is extended to obtain an intercept point on the per cent incompleteness axis. The percentage at this point is seen to be about 117 . Taking 36.8 per cent of this value, 43 per cent is obtained. The major time constant is read as the time to the 43 per cent point on the curve which was plotted for the percentage incompletion; a figure of 48 seconds is thus obtained.

To obtain the first minor time constant, the percentage of difference between curve $A$ and its linear extension to the vertical intercept is plotted. The maximum value of the difference obtained is about 20 per cent. A curve of the difference is plotted and designated as curve B on Fig. 8 . Taking 36.8 per cent of the intercept of curve $B$, a value of approximately 10 seconds is obtained for the first minor time constant. Considering reading limitations of the charts and introduction of unavoidable small inaccuracies in the data reduction process, the value of 10 seconds compares favorably with the 6.07-second figure predicted in Reference 2 for the TE-201 resistance thermometer. A similar procedure was used to obtain all of the time constants given in Table IV. 


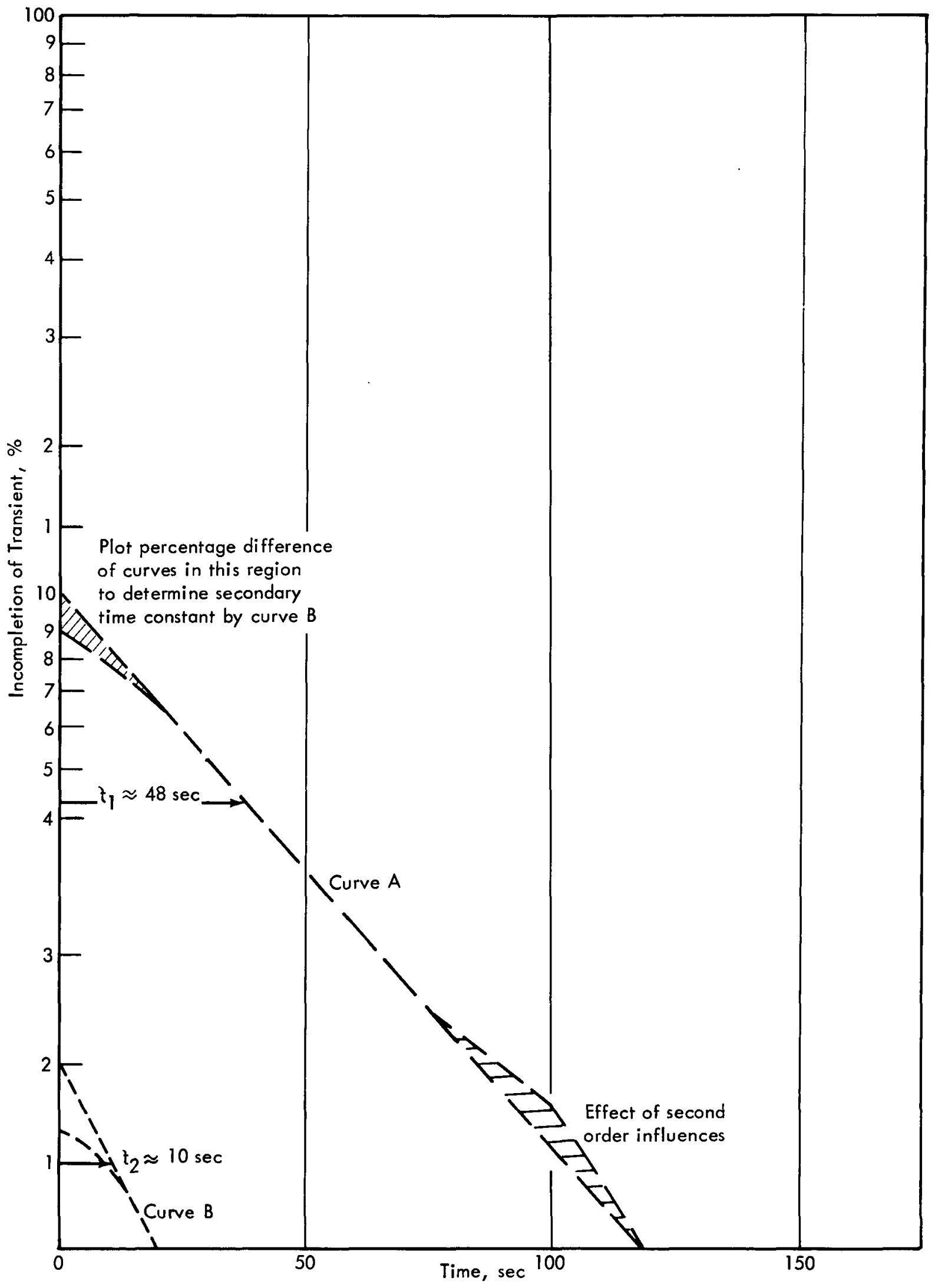

FIG. 8 DETERMINATION OF TIME CONSTANTS FOR TE 201-1 RESPONSE IN SCRAM TEST AT $67 \mathrm{Mwt}$ 


\section{Thermal Transients}

Because of the low heat levels involved, thermal transients at reactor power levels of the order of $20 \mathrm{Mwt}$ and below are essentially insignificant. The 67-Mwt test is of main interest in determining maximum thermal transients from the scram test recordings.

Recordings of reactor outlet sodium temperature (TE-201) obtained in the 67-Mwt scram with operation on two coolant loops have shown temperature fluctuations which were nonperiodic in nature and of significant amplitude and rate of change. Evaluation of this data recorded on magnetic tape was performed on an analog computer. It was found that transients as high as $44^{\circ} \mathrm{F}$ per second had occurred in loop 1 during a temperature fluctuation of $76^{\circ} \mathrm{F}$, while in loop 2 , a transient of $20^{\circ} \mathrm{F}$ per second occurred during a temperature fluctuation of $48^{\circ} \mathrm{F}$. These transients were the predominant ones among the temperature fluctuations which were present in the main decay transients of the TE-201 temperatures. In general, the fluctuations were nonperiodic in nature and had time intervals between peaks ranging from approximately one to five seconds. The maximum design transient for TE-20l and for other key parameters are given in Table V, which was obtained from Reference 1, Appendix A.

The severity of temperature fluctuations and transients which have been encountered is largely the result of 2 -loop operation, where the rate and homogeneity of coolant mixing is poorer than that which would be obtained in operation on three loops. It should be mentioned that the 30 -inch reactor sodium outlet nozzle nearest the core is that of loop No. 2; whereas the nozzles for loops 1 and 3 , equidistant from the core, are more distant therefrom (see Figure 4).

The TE-217-1 detector, which measures reactor outlet temperature, produced a signal which contained fluctuations much more prominent than those of the TE-20l outputs. Because of the relatively low time constant of the TE-217 detector, its response is much faster than that of TE-201. As described under Section III, the TE-217 detectors are sheathed thermocouples having a response of the order of one second for the basic, unmounted unit; however, usable output was not obtained from detector TE-217-2 because of an apparent condition of poor thermal contact between the thermocouple and the thermowell. Analog computer analysis of the signal from TE-217-1, taking into account appropriate coefficients to correct for the lower time constant of the TE-217 detector, provided transient figures of essentially the same magnitude as obtained from the TE-201-1 data. Because of the physical separation of the two detectors, as well as the random nature of the sodium mixing action in the upper reactor plenum, the transient waveforms which were recorded were substantially dis similar. 
TABLE V - MAXIMUM DESIGN TRANSIENTS

Maximum Design Transient

Sensor Location

of/sec $\quad \underline{T},{ }^{\circ} F \quad$ Cycles $\quad \underline{\text { Ref. I Table No. }}$

TE-201 Reactor Outlet

$-15.8$

300

500

102.2

TE-209 Reactor Inlet

$-21.4$

150

102.2

TE-308 Steam Generator Sodium Inlet

40

350

$5 *$

106.9

$\stackrel{\omega}{0}$

TE-301 IHX Secondary Sodium Inlet

30

350

$5 *$

106.5

$\mathrm{TE}-601$

Steam Generator Steam Outlet

40

350

$5 *$

106.9

* The minimum number of cycles used in design was 1000 cycles - in most cases the equipment is capable of withstanding cycles up to the endurance limit. 
Responses of other temperature parameters in the 67-Mwt test were analyzed using Equation (1) in Reference 3 to determine representative values for the maximum thermal transients. The expression is

$$
T_{s}=T_{t}+\left(\tau_{1}+\tau_{c}\right) d T_{t} / d t+\tau_{1} \tau_{c} d^{2} T_{t} / d t^{2}
$$

where

$$
\begin{aligned}
& T_{s}=\text { actual sodium temperature, }{ }^{\circ} \mathrm{F} \\
& T_{t}=\text { measured temperature, }{ }^{\circ} F \\
& T_{1}=\text { time constant of the resistance temperature detector, sec } \\
& T_{c}=\text { time constant of the instrumentation circuit, sec } \\
& t=\text { time, sec }
\end{aligned}
$$

The transient values calculated for TE-115, TE-209, TE-301, TE-308, and TE-601 are given in Table VI along with the values which were obtained for TE-201-1 and TE-201-2 by computer analysis. Also given in Table VI are the detector time constant value $\tau_{1}$ used in making the computations. Inas much as the time constant of the instrumentation equipment $T_{c}$ is small in comparison with the detector time constants, the value of $T_{c}$ was taken as zero in the calculations.

It will be noted that plus and minus values are indicated for the magnitude of change and the rate of change of the TE-201 and TE-301 parameters. The notation is used where the recorded trace was fluctuating.

Except for the values obtained for TE-201-1 and TE-201-2, the maximum transients observed in the 67-Mwt scram test are well below the stipulated maximum value. Although the rates of change of TE-201-2 and TE-201-1 are significantly in excess of the $-15.8^{\circ} \mathrm{F} / \mathrm{sec}$ maximum value stated, the transients are well within the $300^{\circ} \mathrm{F}$ figure given for the maximum magnitude of the change for TE-201.

\section{TABLE VI - MAXIMUM THERMAL TRANSIENTS DERIVED FROM 67-Mwt SCRAM TEST RECORDINGS}

\begin{tabular}{lcccc} 
Parameter & $\begin{array}{c}\text { Detector Time } \\
\text { Constant, sec }\end{array}$ & & $\begin{array}{c}\text { Magnitude } \\
\text { of Change, oF }\end{array}$ & $\begin{array}{c}\text { Rate of } \\
\text { Change, oF }\end{array}$ \\
\cline { 2 - 2 } & 6.07 & & \pm 76 & \pm 44 \\
TE-201-2 & 6.07 & \pm 48 & \pm 20 \\
$\mathrm{TE}-209-2$ & 6.07 & -10.2 & -0.2 \\
$\mathrm{TE}-301-2 \mathrm{D} 1$ & 1.2 & \pm .4 & \pm 1.75 \\
$\mathrm{TE}-308-2$ & 0.25 & -68 & -0.85 \\
$\mathrm{TE}-601-2$ & 25 & -42 & -0.56
\end{tabular}

Note: 1. A \pm before the number indicates that the recorded parameter was fluctuating.

2. Operation was on 2 coolant loops during the 67-Mwt scram test. 


\section{Plant Parameter Values}

Listed in Table VII are the values of the principal plant parameters before and after the scram as read from the strip chart recordings. Performance of the steam system at the power levels of 20 megawatts and below was stable and of little interest for transient studies because of the low power levels involved. Consequently, recordings of steam pressure and feedwater flow were taken only during the 67-Mwt scram. The beforescram values given in Table VII were obtained from the strip chart recording traces with readings taken at a point only a few seconds from the apparent starting point of the scram-produced change. The after-scram values were read at the first region where a change in the parameter was no longer evident. This time interval, which will be referred to herein as the settling of level-off time, is in most cases within 1000 seconds, or approximately 15 minutes, for the parameters recorded.

\section{Parameter Response Characteristics}

To provide information on the nature of the parameter responses without reproducing the actual recorded traces, a brief descriptive commentary on the transient responses obtained is presented below. The trans port delay and major time constant of the principal plant parameters were given in Tables II and IV, respectively.

\section{a. Core Outlet Temperature}

As expected, the decay of the recorded core outlet temper ature (TE-115) was monotonic in all of the scram tests. Two values of settling time were observed: approximately 30 seconds in the $67-$ and $13.3-$ Mwt responses and approximately 20 seconds in the 20 - and $9.5-\mathrm{Mwt}$ responses.

\section{b. Reactor Sodium Outlet Temperature}

Recordings of the reactor sodium outlet temperature exhibited random fluctuations of high amplitude in both the TE-201 and the TE-217 detector outputs in the 67-megawatt (2-loop) test. The beginning of the fluctuations coincided essentially with the beginning of the decay of the recorded temperatures. The fluctuations became most pronounced about 30 seconds after the time of initial appearance and thereafter decayed so as to become indiscernible at 175 seconds in the case of $T E-201$, and at about 205 seconds in the case of TE-217. The settling time of the TE-201 and TE-217 responses was about 600 seconds.

In the 20-Mwt test the TE-201 and TE-217 decays, as recorded, were essentially monotonic, with only a slightly discernible trace of fluctuation. The settling times of the TE-201 and the TE-217 recordings in the 20-Mwt test were approximately 590 seconds. 
Parameter Value

67 Mwt 2-Loop Operation

Temperature Recordings, ${ }^{\circ}$ F
TE-115-9
TE-201-1
TE-201-2
TE-209-2
TE-217-1
TE-217-2
TE-301-2D1
TE-308-2
TE-601-2

Steam Pressure Loop No. 2, psi

Feedwater Flow Loop No. 2, lb/hr

Neutron Flux (Electrometer), amps

20 Mwt 3-Loop Operation

Temperature Recordings, ${ }^{\circ} \mathrm{F}$

TE-115-9

TE-201-1

TE-201-2

TE-201-3

TE-209-3

TE-217-2

TE-217-3

TE-301-3C

TE-308-3

TE-601-2

Neutron Flux (Electrometer), amps

13.3 Mwt 2-Loop Operation

Temperature Recordings, ${ }^{\circ} \mathrm{F}$

TE-115-9

TE-201-1

TE-201-3

TE-209-3

TE-217-1

TE-217-3

TE-301-3C

TE-308-3

TE-601-3

Neutron Flux (Electrometer), amps

9.5 Mwt 2-Loop Operation

Temperature Recordings, ${ }^{\circ} \mathrm{F}$
TE-115-9
TE-201-1
TE-201-3
TE-217-1
TE-217-3
TE-209-3
TE-301-1C
TE-301-3C
TE-308-3
TE-601-3
Neutron Flux (Electrometer), amps
* Detector not functioning
** Not recorded

Before Scram

After Scram

746
666
668
542
652
652
520
586
610
900
$.1 \times 10^{5}$
$.43 \times 10^{-5}$

524

526

528

518

522

540

525

512

516

875

0

$1.1 \times 10^{5}$
$2.43 \times 10^{-5}$

0
500

$<500$

500

506

518

500

$<500$

500

520

0

506

510

512

517.5

512

513

510

508

430

525

$0.45 \times 10^{-5}$

$\begin{array}{cc}542 & \sim 510 \\ 533 & \sim 512 \\ 537 & \sim 517 \\ * * & * * \\ * * & * * \\ 526 & \sim 521 \\ 541 & \sim 533 \\ 540 & \sim 533 \\ 523 & 510 \\ 630 & \sim 523 \\ 0.31 \times 10^{-5} & 0\end{array}$


Recordings of TE-201 and TE-217 in the 13.3-Mwt test both show random fluctuations, becoming most pronounced about 30 seconds after beginning of the temperature decay and diminishing to insignificance at 75 seconds in the case of TE-201, and about 125 seconds in the case of TE-217 responses.

In the 9.5-Mwt test the TE-201-1 decay shows a perceptible degree of fluctuation, becoming most pronounced at about 30 seconds after start of the decay, whereas the TE-201-3 decay is relatively free of fluctuations. TE -217 responses were not recorded during the 9.5-Mwt test as the detectors were not yet connected for use. The fluctuations in the TE201-1 trace diminish to an imperceptible level in about 75 seconds after start of the decay. The settling times of the TE-201 responses were somewhere beyond 500 seconds, which was the duration of the recordings taken.

\section{c. Reactor Inlet Temperature}

The decay of the reactor inlet temperature (TE-209) in the 67-Mwt test exhibited an undershoot to $514^{\circ} \mathrm{F}$ at about 470 seconds after start of the decay, followed by a slight upswing and downswing, with leveloff at approximately 900 seconds.

In the 20-Mwt test, the decay of TE-209 was essentially monotonic, with level-off somewhere beyond 400 seconds - the limit of the recording obtained.

In the 13.3-Mwt test, the decay of TE-209 was perceptibly oscillatory, with about two oscillation cycles occurring before level-off in about 850 seconds after start of the decay.

In the 9.5-Mwt test, decay of TE-209 was perceptibly oscillatory, with one cycle of oscillation taking place well before leveloff, the latter occurring somewhere beyond 500 seconds, the limit of the recording.

\section{d. Steam Generator Sodium Inlet Temperature}

Decay of the steam generator sodium inlet temperature (TE308) was monotonic in the scram tests at all power levels. The level-off times in the 67-, 20-, 13.3- and 9.5-Mwt tests were 545,650,650, and beyond 500 seconds (limit of the recording), respectively.

\section{e. Steam Generator Sodium Outlet Temperature}

In the 67-Mwt test the steam generator sodium temperature recording contained a good deal of "hash", or relatively high frequency fluctuation, before the scram. The peak-to-peak level of the hash as 
evident on the chart was about $5^{\circ} \mathrm{F}$ maximum. Some long period variation in the TE-301 recording was evident up to as well as beyond the instant of reactor scram. The parameter was unstable, precluding analysis for trans port lag and time constant. A sharp drop from approximately 520 to $515^{\circ} \mathrm{F}$ occurred 340 seconds after the scram, followed by an upswing beginning at 495 seconds, then one slight oscillation, with level-off in about 875 seconds.

Decay of TE-301 in the 20-, 13.3- and 9.5-Mwt tests was monotonic, with the traces containing essentially no evidence of hash or high frequency fluctuations as were present in the recording during the 67Mwt test. Level-off occurred at approximately 600 and 500 seconds in the 20- and the 13.3-Mwt tests, respectively, and after 500 seconds (duration of recording) in the $9.5-\mathrm{Mwt}$ test.

\section{f. Water-Steam Temperature}

Decay of the water-steam temperature (TE-60l) was monotonic at all test power levels, with no significant fluctuations apparent. Level-off times were $600,560,500$ seconds in the 67-, 20-, and 13.3-Mwt tests, respectively, and approximately 450 seconds in the $9.5-\mathrm{Mwt}$ test.

\section{g. Feedwater Flow}

This parameter was recorded only in the 67-Mwt test, with flow control being in the manual mode. The response characteristic as recorded exhibited cutback in flow in six essentially distinct steps, i.e., as opposed to a smooth curve, from the initial value of $1.1 \times 10^{5} ; 0.84 \times$ $10^{5} ; 0.54 \times 10^{5} ; 0.41 \times 10^{5} ; 0.34 \times 10^{5}$ and zero $1 \mathrm{~b} /$ hour/loop; the time at which these values were first reached following the scram were 80,200 , $385,425,430$ and 435 seconds, respectively.

\section{h. Regulator Rod Position}

In all of the scram tests, run-down of the regulator rod performed satisfactorily. Run-down velocity was 5.35 inches per minute. The time lag between the instant of scram as defined by the neutron flux decay signal and the start of the run-down was less than one second, about the limit of time resolution on the strip chart recordings.

\section{i. Neutron Flux}

In all the scram tests the recorded trace of the neutron flux parameter exhibited essentially a step change with only a small degree of round-off, due to delayed neutrons. 
0

- 


\section{CONCLUSIONS}

The scram tests which have been conducted at $67-, 20-, 13.3-$, and 9.5-Mwt have demonstrated satisfactory performance of the reactor control system, interlock circuits, and the safety rod raise interlock. Thermal rates of change in the reactor outlet temperature (TE-201) were found to be in excess of the maximum design value in the 67-Mwt test which was conducted with operation on two coolant loops; however, the magnitude of temperature change over which these rates of change occurred was comparatively small and well within the design maximum. It is to be expected that operation on three coolant loops will significantly reduce the rate of change value of the TE-201 transients. The magnitudes of the transients in parameters other than TE-201 have been found substantially below the design maximum values. 


\section{REFERENCES}

1. "Enrico Fermi Hazards Summary Report and Technical Information," Vol. 1-7, as revised, Power Reactor Development Company, March 1964.

2. Wilber, H. A., and Friedland, A. J., "Scram Transients," Nuclear Test Procedure No. 28, Rev. I, Atomic Power Development Associates, Inc., 1966.

3. Ibid, Appendix A.

4. Page, E. M. , and Horne, R. E. , "Flux Mapping Measurements to Determine the Location of the Permanent Detectors in the Enrico Fermi Reactor," APDA-NTS-8, September 1966. 